\title{
Diabetes, Dipeptidyl Peptidase IV and Wound Healing: from Basic Science to Therapeutic Possibilities
}

\author{
Lara Baticic Pucar ${ }^{1 *}$, Alaa Sharbini², Jadranka Varljen ${ }^{1}$, Ester Pernjak Pugel ${ }^{3}$, Antonijo Grcic ${ }^{2}$ and Dijana Detel ${ }^{1}$ \\ 1Department of Medical Chemistry, Biochemistry and Clinical Chemistry, Faculty of Medicine, University of Rijeka, Croatia \\ ${ }^{2}$ Student at the Faculty of Medicine, University of Rijeka, Croatia \\ ${ }^{3}$ Department of Histology and Embryology, Faculty of Medicine, University of Rijeka, Croatia
}

Received: 啙 August 30, 2018; Published: 制 September 10, 2018

*Corresponding author: Lara Baticic Pucar, Department of Medical Chemistry, Biochemistry and Clinical Chemistry, Faculty of Medicine, University of Rijeka, Braće Branchetta 20, 51000 Rijeka, Croatia

\begin{abstract}
Diabetes mellitus, a chronic metabolic disease characterized by different pathological outcomes as a consequence of unsettled hyperglycemia, often accompanied with various complications such as chronic ulcers, represents a major socio-economic health problem. Dipeptidyl peptidase IV or CD26 molecule (DPP IV/CD26), is an omnipresent transmembrane protein with significant involvements in different physiological and pathological processes. It has been recognized as a therapeutic option in the treatment of hyperglycemia, especially in patients suffering from type 2 diabetes, given its capability to regulate the biological activity of incretins, which are major regulators of glucose homeostasis. Furthermore, DPP IV/CD26 has been indicated to be involved in the regulation of inflammatory processes as well as cell proliferation and angiogenesis. New scientific evidence shows that inhibition of DPP IV/CD26 leads to a more efficacious healing of chronic ulcers in diabetic patients as well as in mice models of wounded tissue restoration. However, the role of DPP IV/CD26 in the process of wound healing in hyperglycemia is not entirely known. Our aim was to summarize most important findings on the involvement of DPP IV/CD26 in the regulation of glycemia as well as tissue regeneration and reparation. This work reviews basic biochemical mechanisms and therapeutic possibilities of DPP IV/CD26 inhibition as a good candidate in the therapy of diabetic wound healing.
\end{abstract}

Keywords: CD26 molecule; Diabetes; Dipeptidyl-peptidase IV; Glucose Homeostasis; Hyperglycemia; Chronic Metabolic Disease

\section{Introduction}

\section{Diabetes Disease Overview}

Diabetes (lat. Diabetes Mellitus) is defined as a chronic metabolic disease characterized by several pathological outcomes as a consequence of unsettled hyperglycemia. Numerous processes are involved in the disease development and progression, from autoimmune processes leading to the damage of pancreatic $\beta$-cells that in turn results in insulin deficiency, to the anomalies that cause resistance to the effect of insulin. The main abnormality is a carbohydrate, protein, and fat metabolism disturbance because of the withdrawal of insulin action. This causes long-term disorders and dysfunction of various organs, most of all the eyes, blood vessels, the heart, the nerves and the kidneys [1]. Diabetes, according to its etiopathogenesis, is divided into type 1 , type 2 and gestational diabetes, which could arise in pregnant women. In type 1 diabetes, a complete cessation of insulin secretion induced most probably by an autoimmune process of beta cell destruction is present.

Type 2 diabetes, a much more frequent entity, is characterized by a $8+$ combination of insulin resistance in different cell types and a compensatory insulin secretion disorder. People suffering from this type of diabetes are characterized by intraabdominal obesity that is associated with deficiency or resistance to insulin, hypertension, and dyslipidemia. The consequences of this disease are numerous, primarily hyperglycemia is manifested, and whose symptoms are polyuria, polydipsia, weight loss, blurred vision and polyphagia. In chronic hyperglycemia, growth disorders and susceptibility to certain infections may also occur. Uncontrolled 
acute diabetes can have life-threatening hyperglycemia episodes with ketoacidosis or non-ketone hyperosmolar syndrome. The number of patients diagnosed with diabetes mellitus in 2011 was estimated at 366 million people, of which $90 \%$ had suffered from type 2 diabetes. Unfortunately, the prevalence of diabetes is very high and the number of patients continues to grow, and therefore it is necessary to encourage each country to take preventive and curative measures like changing nutrition habits and generally the way of life $[1,2]$.

\section{Complications in Diabetes}

Bases of lack of insulin action on target tissues in diabetics could be disorders of insulin secretion and/or reduced sensitivity of tissues to insulin, as mentioned previously. Complications that occur in patients with diabetes may be numerous, including cardiovascular diseases and risks, then macro and microvascular complications and chronic foot ulcers. The major cause of death in diabetics are cardiovascular complications that include hypertension and dyslipidemia. Microvascular complications include nephropathy, retinopathy, neuropathy and chronic foot ulcer [3]. Microangiopathies and macroangiopathies are manifested as an effect on capillaries and blood vessels throughout the organism and they include impacts on different tissues and organs, mainly eyes and kidneys. The most common consequence of retinopathy in diabetics is blindness. In the absence of insulin, the permeability and ability of glucose to enter into cells in vascular and nerve tissues increases. Compensation mechanisms can, therefore, induce impairment of blood vessels and nerves. The aforementioned complications can affect the dynamics of wound healing patients suffering from diabetes that was caused by the weakened complex mechanisms of tissue regeneration [4]. One of the principal reasons of morbidity in patients with diabetes are chronic ulcers that greatly affect the quality of life and cause suffering and pain of patients. It occurs in $15 \%$ of all diabetics and causes $84 \%$ of total lower extremity amputations associated with this disease. It has been shown that in as many as $25 \%$ of type 2 diabetic patients microvascular complications are present at disease diagnosis, meaning that diabetes is present for more than 5 years. The pathophysiology is very complex, and complications such as macroangiopathy, microangiopathy and neuropathy contribute to the development of diabetic wounds [5].

\section{Therapeutic Approaches to Diabetes}

In order to diminish the risk for future complications, the key is to identify a patient or person with the predisposition of diabetes as soon as possible. Factors that pose a risk to diabetes are obesity, hypertension, and family history of diabetes. To diagnose both types of diabetes, simple tests are used, such as random plasma testing, oral glucose tolerance test, fructosamine test, and other diagnostic tests. In the further treatment of patients, it is most important to accomplish a balanced treatment by achieving stable euglycaemia. This can be realized by appropriate nutrition and oral antihyperglycemic therapy or by intravenous insuline application. In patients with type 1 diabetes, customized insulin therapy is applied, and it lasts for a lifetime. Patients with type 2 diabetes could also receive insulin therapy. Surgical treatments of the pancreas also represent an option. In type 2 diabetes, circulating levels of glucose and fatty acids that promote beta cell dysfunction are present. In order to renew beta cells, there is a possibility of transplanting pancreatic islet cells that are rich with capillary nets [2]. After transplanting islets, for successful recovery, vascularization factors such as vascular endothelial growth factor (VEGF), which promotes angiogenesis, are crucial. Another important factor is glucagon-like peptide 1 (GLP-1), which in vivo acts to expand the mass of the islet by increasing the number of beta cells and encouraging neogenesis of the islet [6]. GLP-1 is a very important regulator of glucose metabolism in humans and has a biological effect that is manifested to stimulate insulin secretion. Furthermore, it inhibits glucagon secretion, prolongs gastric emptying time and provokes a sense of satiety. Because of these effects, GLP-1 is a molecule of great therapeutic importance in the treatment of type 2 diabetes [7]. Its availability depends mainly on the activity of dipeptidyl-peptidase IV (DPP IV/CD26), a molecule that has catalytic activity on GLP1. Using DPP IV inhibitors in type 2 diabetes therapy, this allows the increase of GLP-1 half-life time and thus enhances metabolic control [8].

\section{Dipeptidyl Peptidase IV (DPP IV/CD26) - Molecular and Biological Properties}

Dipeptidyl peptidase IV, also known as molecule CD26 (DPP IV/CD26) is a serine protease found on the cell surface of different cell types, belonging to the prolil-oligopeptidase family [9]. DPP IV/ CD26 is present in living organisms in a soluble and membranebound form. The soluble form is circulating in plasma and other body fluids, while the membrane form is found on the surface of a large number of different cells. This molecule is of growing scientific interest because of its wide spectrum of activity in various processes in the body, such as role in glucose metabolism and role of diagnostic or prognostic markers for different chronic diseases [9]. The specific activity of DPP IV/CD26 is the catalytic degradation of the dipeptides from the N-terminal part of protein chains with proline or alanine at the penultimate site in amino acid sequences [10]. Considering the type of cells expressing DPP IV/CD26, it has a multitude of functions. Thus, in the gastrointestinal system the most pronounced activity of DPP IV/CD26 is proteolysis, among which an important place takes degradation of GLP-1 and glucose dependent insulinotropic polypeptide [11]. DPP IV/CD26 has also a role as a receptor for collagen and fibronectin $[12,13]$.

In vitro studies have shown a causal connection between DPP IV/CD26 and collagen type I and III [14]. DPP IV/CD26 forms with fibronectin III a complex that has an influence on the 
growth potential of tumor cells that leads to cancer development and progression [15]. It also participates in the processes of cell adhesion, migration and apoptosis, crucial mechanisms in wound healing [13]. Moreover, DPP IV/CD26 has a proteolytic effect on neuropeptide Y (NPY), which stimulates growth factors VEGF and basic fibroblast growth factor (bFGF), which has a positive effect on myocardial activity and maturation of new blood vessels. DPP IV/ CD26 has been shown to have the ability to regulate inflammatory processes, proliferation and angiogenesis $[15,16]$. DPP IV/CD26 is also an important factor in the immune system. It has been shown that it is involved in the cell proliferation process, differentiation of lymphocyte B and NK cells $[17,18]$, apoptosis process, complex process of activating $\mathrm{T}$ lymphocytes in vivo and in vitro conditions $[10,19]$ and in autoimmune processes [15].

DPP IV/CD26 represents a receptor for adenosine deaminase (ADA) on the surface of lymphocytes $\mathrm{T}$ [20], which is found in all tissues that are important in the development and function of lymphatic tissues. Furthermore, it shows an essential role in purine metabolism [21]. The complex formed by DPP IV/CD26 and ADA association acts to decrease the adenosine level. High adenosine concentrations are toxic and under these conditions, an inhibition of lymphocyte T proliferation occurs [22]. Another major role of DPP IV/CD26 has been recognized in the signal transduction process in cells. Main chemokines included in the signal transduction process such as eotoxin, MIG, LD78 $\beta$, MDC and SDF- $1 \alpha$ are substrates of DPP IV/CD26, which in turn has the ability to activate or inactivate their biological function. Therefore, many chemokines which are inactivated and whose ability to activate signal via their receptors are under the direct control of DPP IV/CD26 [15,23]. The ability of DPP IV/CD26 to bind on the cytoplasmic domain of CD45 has also been shown, and its localization on lipid rafts was proved [24].

\section{DPP IV/CD26 and Diabetes}

DPP IV/CD26 indeed has been shown to have a major role in the regulation of glucose homeostasis. The GLP-1 molecule, which is an important regulator of glucose metabolism since it stimulates insulin secretion, inhibits glucagon secretion, prolongs gastric emptying time, provokes a sense of satiety, and thus represents an important therapeutic target in diabetes therapy [7,25]. It is known that DPP IV/CD26 proteolytically cleaves GLP-1 [11]. The catalytic action of DPP IV/CD26 on GLP-1 has prompted the use of DPP IV/CD26 inhibitors in type 2 diabetic patients because they allow the increase of GLP-1 half-life and thus enhance metabolic control, which facilitates the treatment of patients with diabetes [8]. Since GLP-1 half-life lasts only 2 to 3 minutes because of DPP IV/CD26 activity, the use of DPP IV/CD26 inhibitors increases the half-life time of GLP-1 and other hormones that affect glucose metabolism like gastric inhibitory peptide (GIP) and vasoactive intestinal peptide (VIP) [26]. In type 2 diabetes, such inhibitors can be used together with other anti-diabetic therapies such as metformin. At the beginning of 2000, the first clinical evidence of the role of DPP IV/CD26 inhibitors in the treatment of this disease was recorded [27]. The most commonly used DPP IV/CD26 inhibitors in type 2 diabetic therapy are saxagliptin, sitagliptin and vildagliptin. Inhibitors differ according to chemical properties, strength of action and time of action and other pharmacokinetic properties. Their common feature is to inhibit the catalytic activity of DPP IV/CD26 and successfully lower blood glucagon levels and consequently have a positive impact in controlling glycemia in patients with diabetes [28,29].

In 2002, a study from a pharmaceutical company showed that over four weeks of treatment with DPP IV/CD26 inhibitor at a dose of $100 \mathrm{mg}$ daily reduce blood glucose levels by about $1 \mathrm{mmol} / \mathrm{L}$ in patients with type 2 diabetes [30]. The impact of DPP IV/CD26 and its inhibitors on glucose homeostasis is presented on Figure 1. Furthermore, a study in diabetic mice treated with DPP IV/CD26 inhibitors has shown a reduction in blood glucose concentration, but also an increase in the number of beta cells in the pancreas, due to which the insulin concentration increased [31]. Moreover, sitagliptin shown an effect of increasing the proliferation of endothelial cells within the grafts. Localization of cells forming micro-vascular vessels and glucagon-positive cells around beta cells was found, suggesting that sitagliptin influences vascularization by activating the VEGF-A/VEGF-B signal pathway and consequently contributing to the improvement of functional blood flow to grafts. The obtained results show a positive effect of sitagliptin on the secretion of VEGF in transplanted porcine islets. Indeed, it was found to contribute to the process of cell proliferation and as well as neovascularization by enhancing the expression of VEGFR-2 [6].

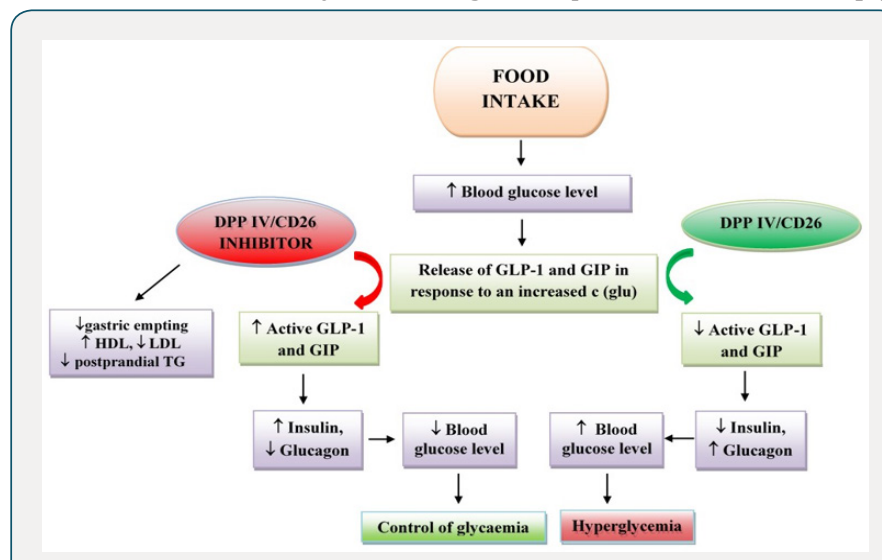

Figure 1: Impact of DPP IV/CD26 and its inhibitors on glucose homeostasis.

The use of linagliptin in mice with diabetes resulted in decreased blood glucose levels and acceleration of re-epithelialization of wounds due to increased levels of active GLP-1 in wound tissue lysates. In treated mice, reduced levels of neutrophils and macrophages were recorded [32]. Another positive effect has been shown by the DPP IV/CD26 inhibitor vildagliptin where in conducted clinical trials has led to faster healing of chronic ulcer in 
diabetics, with faster wound closure compared to the control group. It is assumed that this is a consequence of the effect of vildagliptin on increasing the VEGF level and the transcription factor HIF- $1 \alpha$, which plays a major role in neovascularization [33]. By increasing the level of cytokine and growth factors such as SDF-1 $\alpha$ in plasma and the number of endothelial precursor cells in circulation, DPP IV/CD26 inhibitors could have a positive effect on the wound healing process [34]. However, DPP IV/CD26 inhibitors may also have numerous side effects such as allergic reactions, hypoglycemia and hypoglycemic shock [35]. Many pharmaceutical company researches are trying to improve the existing inhibitors to prevent side effects and to increase their effectiveness in the treatment of type 2 diabetes.

\section{DPP IV/CD26 and Wound Healing}

Wound healing is a challenging and multifaceted process that encompasses a large number of complex biochemical and cellular mechanisms whose outcome is mainly focused on tissue reparation and restoration of its function. This process can be divided into three phases that overlap each other. The homeostasis or the zero phase occurs first and immediately after it the inflammatory phase (phase I) begins. Then starts the proliferation phase or phase II, followed by the maturation or remodeling phase (phase III). Interruption or prolongation of individual phases can lead to delayed healing of wounds and other difficulties in the process itself [36]. In homeostasis, the activation and aggregation of thrombocytes occurs, which interact with collagen and create a blood clot that stops bleeding and makes a barrier that prevents penetration of microorganisms. A blood clot contains growth factors necessary for the next phases of the healing process and serves as a medium for migrating inflammatory cells $[37,38]$.

Degranulation of thrombocytes in blood clot releases growth factors such as epidermal growth factor (EGF), platelet-derived growth factor (PDGF) and transforming growth factor- $\beta$ (TGF- $\beta$ ), which stimulate the attraction of inflammatory cells to the site of injury, thus starting the inflammatory phase. TGF- $\beta$ has a role in attracting monocytes that differentiate into macrophages whose function is phagocytosis of the remaining microorganisms, tissue residues and other cells. Macrophages have the ability to secrete a number of coagulation factors and cytokines involved in inflammatory processes such as TNF- $\alpha$, IL-1, IL-6, IL-8, IL-12 and growth factors such as PDGF, TGF- $\beta$, fibroblast growth factor (FGF) and EGF [39]. Their importance is in connecting non-specific and specific immunity [40]. It is known that regulated on activation normal T-cell (RANTES), another important substrate of DPP IV/ CD26, plays a major role in the activation of macrophages in a mouse model of cutaneous wound repair [41]. Similarly, studies in mice with macrophage deficiency, confirmed the critical role of macrophages in the process of neovascularization of the wounded tissue [42].

Furthermore, macrophages and keratinocytes are among the major cells that excrete the VEGF, a growth factor that stimulates the angiogenesis process [43]. In the wounded area, T lymphocytes act to increase blood vessel permeability and influence the activity of fibroblasts in the wound healing process [44]. The inflammatory phase protects the organism from infection, cleanses the wound and promotes cell proliferation. The role of macrophages is directed on coordinating the transition of the inflammatory phase to the proliferation phase [45]. In the proliferation phase, under the influence of TGF- $\beta$, it comes to the stimulation of fibroblasts and the synthesis of other substances such as collagen, fibronectin, proteoglycan and elastin. Under the influence of growth factor such as TGF- $\beta$, VEGF and FGF, angiogenesis occurs. The process of growth of new vascular vessels from small venules and capillaries at the site of injury is crucial, and thus the tissue becomes refunctional [38]. Since DPP IV/CD26 exerts an immunomodulative role and is involved in the regulation of macrophage activity as well, it can be assumed that the deficiency of the DPP IV/CD26 molecule has a potentially positive effect on the expression of macrophages and consequently on the secretion of VEGF, which ultimately leads to enhanced angiogenesis $[46,47]$. The involvement of DPP IV/ CD26 in the mechanisms of tissue regeneration and reparation via its different biological functions is schematically represented on Figure 2.

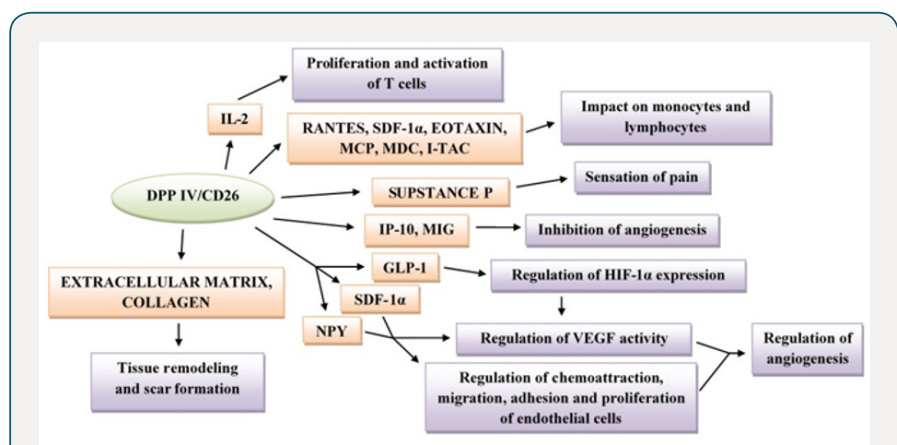

Figure 2: Mechanisms of DPP IV/CD26 involvement in the wound healing process.

The wound healing process is disturbed in the presence of hyperglycemia due to various internal and external factors [48]. Pathophysiological abnormalities in diabetes lead to delayed wound healing since the process of tissue reparation and regeneration is not harmonized. Internal factors such as vascular complications, neuropathy, and other hyperglycemia-induced difficulties lead to worsening of wound healing in diabetic ulcers [49]. External factors that affect on wound healing include mechanical stress or repeated traumas that cause wound infections, then callus formation and re-creation of the ulcer. In diabetes, high glucose concentrations reduce the proliferation and differentiation of keratinocytes, chemotaxis and phagocytosis in the initial stage of wound healing and influence the concentrations of growth factors and cytokines. In diabetic wounds, deposition of fibronectin and collagen in excessive amounts is present $[50,51]$.

DPP IV/CD26, like previously mentioned, is of pronounced 
importance in various processes in the organism, from physiological ones to those of pathological origin [52]. Numerous roles of DPP IV/ CD26 demonstrate its importance in the regulation of the biological activity of a multitude of its substrates such as chemokines and cytokines, and indirectly in modulating the immune response. An important role of DPP IV/CD26 in the wound healing process is participation in the degradation of the extracellular matrix, then cell adhesion, migration and angiogenesis. DPP IV/CD26 is involved in the degradation of the extracellular matrix by binding to adenosine deaminase and thus influences the degradation of collagen, fibronectin and laminin [53]. DPP IV/CD26 shows a stimulatory action on the proliferation of lymphocytes $\mathrm{T}$ and on chemokine secretion, that plays an essential role in the inflammatory phase, in the migration of inflammatory cells. Due to a longer lasting of the inflammatory phase in the wound healing process, chronic wounds can occur, and consequently permanent tissue damage [54]. The angiogenic properties of SDF- $1 \alpha$ are also under influence of the enzymatic activity of DPP IV/CD26. Furthermore, NYP is a substrate of DPP IV/CD26, and its proteolytic activity results in termination of NYP activity on the Y1 receptor subtype that promotes vasoconstriction and cell proliferation. Likewise, after the NYP cleavage, changes in regulation of angiogenesis and contraction in the smooth muscles of blood vessels occur [55]. At the stage when hypoxic conditions occur, GLP-1 substrate of DPP IV/CD26 regulates HIF-1 $\alpha$, a factor that regulates expression of VEGF that stimulates angiogenesis and neovascularization and thus affects wound healing. In the case of a low level of VEGF in diabetics, poor vascularization and slower recovery of the wound occurs [56]. DPP IV/CD26 likewise acts proteolytically on the chemokine IP-10, whose role is recruiting NK cells, and which shows the ability to reduce chemotaxis of immune cells and to inhibit angiogenesis. This results in an unsuccessful recovery of blood vessels and increases the tendency for ulcers and dehiscence [57]. Mechanisms of DPP IV/CD26 inhibitors on the process of tissue reparation and regeneration are schematically presented on Figure 3.

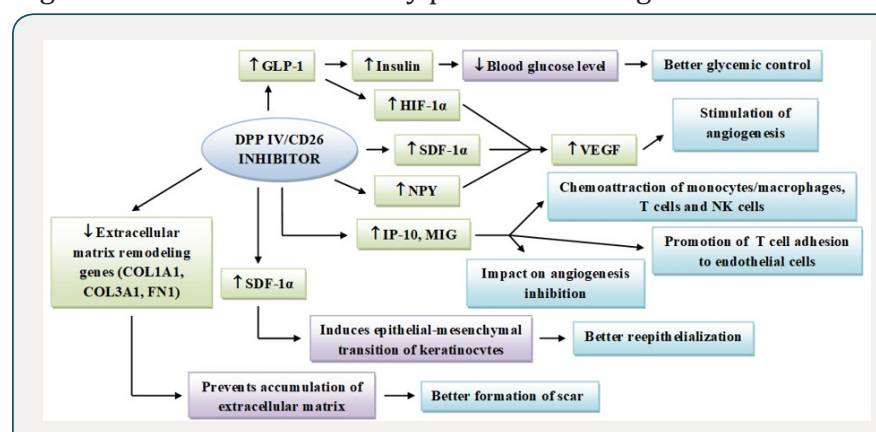

Figure 3: Impact of DPP IV/CD26 inhibitors on the process of tissue reparation and regeneration.

Most recent data and clinical evidence designate that DPP IV/ CD26 inhibitors are highly effective and safe as therapeutic options as well as in the elderly, in patients suffering from different stages of renal failure as well as chronic ulcers since they are able to improve glycemic control with little risk of hypoglycemia at the same time. Moreover, several randomized-controlled studies have revealed that the usage of DPP IV/CD26 inhibitors in combination with insulin represents a good substitute to high-insulin treatment in hospitalized patients suffering from type 2 diabetes [58]. In conclusion, given the neuroimmunomodulative and enzymatic properties of DPP IV/CD26, especially with regard to its substrates involved in maintaining glucose homeostasis as well as positive impacts on tissue regeneration and reparation, this molecule is a good candidate for therapeutic approaches in diabetic patients suffering from chronic ulcers. However, further studies are necessary in order to investigate possible side-effects of long-term use DPP IV/CD26 inhibitors, given the associated immunological effects on regulatory mechanisms such as T cell homeostasis [59].

\section{Acknowledgment}

This work was supported by the University of Rijeka, Croatia (grant number 13.06.1.2.26.).

\section{References}

1. American Diabetes Association (2010). Diagnosis and Classification of Diabetes Mellitus. Diabetes Care 33: S62-S69.

2. Baynes HW (2015) Classification, pathophysiology, diagnosis and management of diabetes mellitus. J Diabetes Metab 6: 541.

3. American Diabetes Association (2015) Standards of Medical Care in Diabetes 2015 Abridged for Primary Care Providers. Clin Diabetes 33: 97-111.

4. Saboo A, Rathnayake A, Vangaveti VN, Malabu UH (2016) Wound healing effects of dipeptidyl peptidase-4 inhibitors: An emerging concept in management of diabetic foot ulcer - A review. Diabetes Metab Syndr 10(2): 113-119.

5. Marfella R, Sasso FC, Rizzo MR, Paolisso P, Barbieri M, et al. (2012) Dipeptidyl peptidase 4 inhibition may facilitate healing of chronic foot ulcers in patients with type 2 diabetes. Exp Diabetes Res 2012: 892706.

6. Samikannu B, Chen C, Lingwal N, Padmasekar M, Engel FB, et al. (2013) Dipeptidyl Peptidase IV inhibition activates creb an improves islet vascularization through VEGF-A/VEGFR-2 signaling pathway. PLoS ONE 8: e82639.

7. Deacon CF (2004) Therapeutic strategies based on glucagon-like peptide 1. Diabetes 53: 2181-2189.

8. Koivisto V (2008) Discovery of dipeptidyl-peptidase IV - a 40-year journey from bench to patient. Diabetologia 51: 1088-1089.

9. Rosenblum JS, Kozarich JW (2003) Prolyl peptidases: a serine protease subfamily with high potential for drug discovery. Curr Opin Chem Biol $7(4): 496-504$.

10. Boonacker E, Van Noorden CJ (2003) The multifunctional or moonlighting protein CD26/DPPIV. Eur J Cell Biol 82: 53-73.

11. Drucker DJ, Nauck MA (2006) The incretin system: glucagon-like peptide-1 receptor agonist and dipeptidyl peptidase-4 inhibitors in type 2 diabetes. Lancet 368(9548): 1696-1705.

12. Aliyari Serej Z, Ebrahimi Kalan A, Mehdipour A, Nozad Charoudeh H (2017) Regulation and roles of CD26/DPPIV in hematopoiesis and diseases. Biomed Pharmacother 91: 88-94.

13. Wang XM, Yu DM, Mc Caughan GW, Gorrell MD (2006) Extra-enzymatic roles of DPIV and FAP in cell adhesion and migration on collagen and fibronectin. Adv Exp Med Biol 575: 213-222. 
14. Löster K, Zeilinger K, Schuppan D, Reutter W (1995) The cysteine-rich region of dipeptidyl peptidase IV (CD 26) is the collagen binding site. Biochem Biophys Res Commun 217(1): 341-348.

15. Yu DM, Yao TW, Chowdhury S, Nadvi NA, Osborne B et al. (2010) The dipeptidyl peptidase IV family in cancer and cell biology. FEBS J 277(5): 1126-1144.

16. Matheeussen V, Jungraithmayr W, De Meester I (2012) Dipeptidyl peptidase 4 as a therapeutic target in ischemia/reperfusion injury. Pharmacol Ther 136(3): 267-282.

17. Ohnuma K, Takahashi N, Yamochi T, Hosono O, Dang NH, et al. (2008) Role of CD26/dipeptidyl peptidase IV in human $\mathrm{T}$ cell activation and function. Front Biosci 13: 2299-2310.

18. Bühling F, Junker U, Reinhold D, Neubert K, Jäger L, et al. (1995) Functional role of CD26 on human B lymphocytes. Immunol Lett 45(12): 47-51.

19. Ohnuma K, Hatano R, Komiya E, Otsuka H, S Itoh, T, et al. (2018) A novel role for CD26/dipeptidyl peptidase IV as a therapeutic target. Front Biosci 23: 1754-1779.

20. Yu DM, Slaitini L, Gysbers V, Riekhoff AG, Kähne T, et al. (2011) Soluble CD26/dipeptidyl peptidase IV enhances human lymphocyte proliferation in vitro independent of dipeptidyl peptidase enzyme activity and adenosine deaminase binding. Scand J Immunol 73(2): 102111.

21. Gorrell MD, Gysbers V, Mc Caughan GW (2001) CD26: A multifunctional integral membrane and secreted protein of activated lymphocytes. Scand J Immunol 54: 249-264.

22. Dong RP, Kameoka J, Hegen M, Tanaka T, Xu Y, et al. (1996) Characterization of adenosine deaminase binding to human CD26 on T cells and its biologic role in immune response. J Immunol 156(4): 13491355

23. Liu Z, Christensson M, Forslöw A, De Meester, Sundqvist KG (2009) A CD26-controlled cell surface cascade for regulation of T cell motility and chemokine signals. J Immunol 183(6): 3616-3624.

24. Ishii T, Ohnuma K, Murakami A, Takasawa N, kobayashi S, et al. (2001) CD26-mediated signaling for $\mathrm{T}$ cell activation occurs in lipid rafts through its association with CD45RO. Proc Natl Acad Sci USA 98(21): 12138-12143.

25. Kreymann B, Williams G, Ghatei MA (1987) Bloom SR Glucagon-like peptide-1 7-36: a physiological incretin in man. Lancet 2(8571): 13001304.

26. Baggio LL, Drucker DJ (2007) Biology of incretins: GLP-1 and GIP. Gastroenterology 132(6): 2131-2157.

27. Cahn A, Cernea S, Raz I (2016) An update on DPP-4 inhibitors in the management of type 2 diabetes. Expert Opin Emerg Drugs 21(4): 409419.

28. Deacon CF, Holst JJ (2013) Dipeptidyl peptidase-4 inhibitors for the treatment of type 2 diabetes: comparison, efficacy and safety. Expert Opin Pharmacother 14(15): 2047-2058.

29. Ahrén B, Landin Olsson M, Jansson PA, Svensson M, Holmes D, et al. (2004) Inhibition of dipeptidyl peptidase-4 reduces glycemia, sustains insulin levels, and reduces glucagon levels in type 2 diabetes. J Clin Endocrinol Metab 89: 2078-2084.

30. Ahrén B, Simonsson E, Larsson H, Landin Olsson M, Torgeirsson H, et al. (2002) Inhibition of dipeptidyl peptidase IV improves metabolic control over a 4-week study period in type 2 diabetes. Diabetes Care 25: 869875.

31. Röhrborn D, Wronkowitz N, Eckel J (2015) DPP4 in diabetes. Front Immunol 6: 386.

32. Schürmann C, Linke A, Engelmann Pilger K, Steinmetz C, Mark M, et al. (2012) The dipeptidyl peptidase-4 inhibitor linagliptin attenuates inflammation and accelerates epithelialization in wounds of diabetic ob/ob mice. J Pharmacol Exp Ther 342: 71-80.

33. Marfella R, Sasso FC, Rizzo MR, Paolisso P, Barbieri M, et al. (2012) Dipeptidyl peptidase 4 inhibition may facilitate healing of chronic foot ulcers in patients with type 2 diabetes. Exp Diabetes Res 2012: 892706.

34. Fadini GP, Boscaro E, Albiero M, Menegazzo L, Frison V, et al. (2010) The oral dipeptidyl peptidase-4 inhibitor sitagliptin increases circulating endothelial progenitor cells in patients with type 2 diabetes: Possible role of stromal derived factor-1alpha. Diabetes Care 33(7): 1607-1609.

35. Palalau AI, Tahrani AA, Piya MK, Barnett AH (2009) DPP-4 inhibitors in clinical practice. Postgrad Med 121(6): 70-100.

36. Lloyd G, Friedman G, Jafri S, Schultz G, Fridman A, et al. (2010) Gas Plasma: Medical Uses and Developments in Wound Care. Plasm Proc and Polym 7: 3-4.

37. Werner S, Grose R (2003) Regulation of wound healing by growth factors and cytokines. Physiol Rev 83(3): 835-870.

38. Diegelmann RF, Evans MC (2004) Wound healing: an overview of acute, fibrotic and delayed healing. Front Biosci 9: 283-289.

39. Barrientos S, Stojadinovic O, Golinko MS, Brem H, Tomic Canic M (2008) Growth factors and cytokines in wound healing. Wound Repair Regen 16: 585-601.

40. Andreis I, Batinić D, Čulo F (2010) i sur. Imunologija, sedmo, obnovljeno i dopunjeno izdanje; Medicinska naklada. Zagreb PP: 41-44.

41. Frank S, Kampfer H, Wetzler C, Stallmeyer B, Pfeilschifter J (2000) Large induction of the chemotactic cytokine RANTES during cutaneous wound repair: a regulatory role for nitric oxide in keratinocyte-derived RANTES expression. Biochem J 347(1): 265-273.

42. Brancato SK, Albina JE (2011) Wound macrophages as key regulators of repair: origin, phenotype, and function. Am J Pathol 178(1): 19-25.

43. Hsu CW, Poché RA, Saik JE, Ali S, Wang S, et al. (2015) i sur. Improved Angiogenesis in Response to Localized Delivery of MacrophageRecruiting Molecules. PLoS One 10: e0131643.

44. Peterson JM, Barbul A, Breslin RJ, Wasser krug HL, Efron G (1987) Significance of T-lymphocytes in wound healing. Surgery 102: 300-305.

45. Harding KG, Morris HL, Patel GK (2002) Science, medicine and the future: healing chronic wounds. BMJ 324(7330): 160-163.

46. Baticic L, Detel D, Kucic N, Buljevic S, Pugel EP, et al. (2011) Neuroimmunomodulative properties of dipeptidyl peptidase IV/CD26 in a TNBS-induced model of colitis in mice. J Cell Biochem 112(11): 3322-3333.

47. Baticic Pucar L, Pernjak Pugel E, Detel D, Varljen J (2017) Involvement of DPP IV/CD26 in cutaneous wound healing process in mice. Wound repair and regeneration 25(1): 25-40.

48. Qing C (2017) The molecular biology in wound healing \& non-healing wound. Chin J Traumatol, 20: 189-193.

49. Greenhalgh DG (2003) Wound healing and diabetes mellitus. Clin Plast Surg 30(1): 37-45.

50. Tsourdi E, Barthel A, Rietzsch H, Reichel A, Bornstein SR (2013) Current aspects in the pathophysiology and treatment of chronic wounds in diabetes mellitus. Biomed Res Int 2013: 385641.

51. Falanga V (2005) Wound healing and its impairment in the diabetic foot. Lancet 366: 1736-1743.

52. Waumans Y, Baerts L, Kehoe K, Lambeir AM, De Meester I (2015) The dipeptidyl peptidase family, prolyl oligopeptidase and prolyl carboxypeptidase in the immune system and inflammatory disease, including atherosclerosis. Front Immunol 6: 387.

53. Itou M, Kawaguchi T, Taniguchi E, Sata M (2013) Dipeptidyl peptidase-4: A key player in chronic liver disease. World J Gastroenterol 19(15): 2298-2306. 
54. Wang PH, Huang BS, Horng HC, Yeh CC, Chen YJ (2017) Wound healing. J Chin Med Assoc 17: 30308-30318.

55. Abe K, Tilan JU, Zukowska Z (2007) NPY and NPY receptors in vascular remodeling. Curr Top Med Chem 7(17): 1704-1709.

56. Parvardia JK, Keswani SG, Vaikunth S, Mldonado AR, Marwan A et al (2007) Role of VEGR in small bowel adaptation after resection: the adaptive response is angiogenesis dependent. Am J Physiol Gastrointest Liver Physiol 293(3): 591-598.

57. Metzemaekers M, Van Damme J, Mortier A, Proost P (2016) Regulation of chemokine activity A focus on the role of dipeptidyl peptidase IV/ CD26. Front Immunol 7: 483.

58. Gomez Peralta F, Abreu C, Gomez Rodriguez S, Barranco RJ, Umpierrez GE (2018) Safety and Efficacy of DPP4 Inhibitor and Basal Insulin in Type 2 Diabetes: An Updated Review and Challenging Clinical Scenarios. Diabetes Ther.

59. Klemann C, Wagner L, Stephan M, Von Hörsten S (2016) Cut to the chase: a review of CD26/dipeptidyl peptidase-4's (DPP4) entanglement in the immune system. Clin Exp Immunol 185(1): 1-21.

\section{(C) This work is licensed under Creative}

To Submit Your Article Click Here: Submit Article

DOI: $10.32474 /$ OAJBEB.2018.02.000147

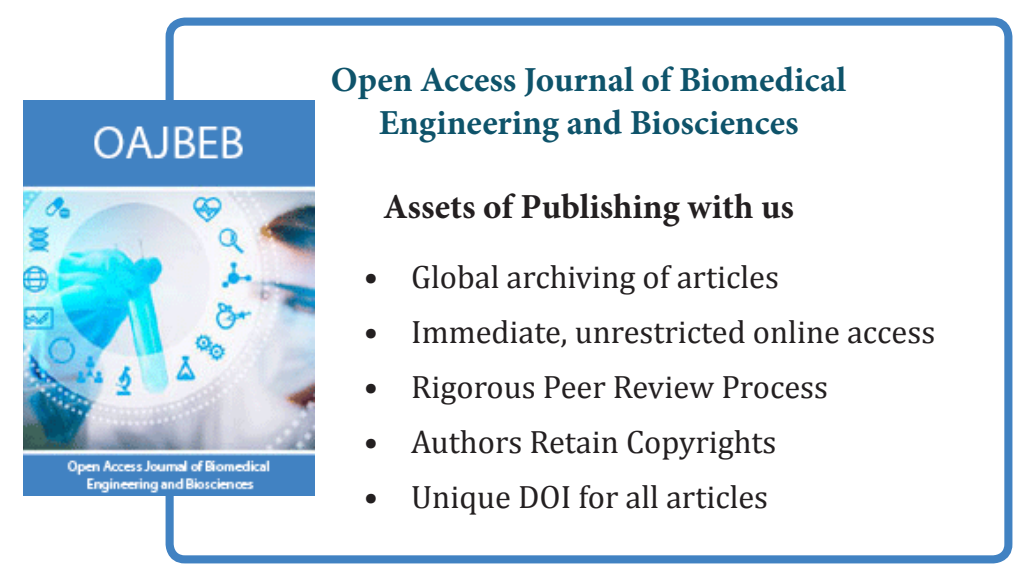

